\title{
Buruli Ulcer and HIV Coinfection: Cases in Togo
}

\author{
Menssah Teko ${ }^{1,2}$, Mounerou Salou ${ }^{3}$, Fifonsi A. Gbeasor-Komlanvi ${ }^{3,4}$, \\ Abla Ahouefa Konou ${ }^{3}$, Yaovi Ameyapoh ${ }^{2,5^{*}}$ \\ ${ }^{1}$ Centre Hospitalier Régional de Tsévié, Tsévié, Togo \\ ${ }^{2}$ Ecole Supérieure des Techniques Biologiques et Alimentaires, Université de Lomé, Lomé, Togo \\ ${ }^{3}$ Département de Pharmacie, Faculté des Sciences de la Santé, Université de Lomé, Lomé, Togo \\ ${ }^{4}$ Centre Africain de Recherche en Epidémiologie et en Santé Publique, Lomé, Togo \\ ${ }^{5}$ Laboratoire de Microbiologie et de Contrôle de Qualité des Denrées Alimentaires, Université de Lomé, Lomé, Togo \\ Email:tmroger2001@gmail.com,mounerous@gmail.com, fifonsi.gbeasor@gmail.com, \\ ekonou@yahoo.fr, ^ameyapoh.blaise@gmail.com
}

How to cite this paper: Teko, M., Salou, M., Gbeasor-Komlanvi, F.A., Konou, A.A. and Ameyapoh, Y. (2020) Buruli Ulcer and HIV Coinfection: Cases in Togo. World Journal of AIDS, 10, 159-169.

https://doi.org/10.4236/wja.2020.103014

Received: July 14, 2020

Accepted: August 23, 2020

Published: August 26, 2020

Copyright () 2020 by author(s) and Scientific Research Publishing Inc. This work is licensed under the Creative Commons Attribution International License (CC BY 4.0). http://creativecommons.org/licenses/by/4.0/

\begin{abstract}
Background: In Togo, as in all sub-Saharan countries, the burden of HIV infection remains high. The registration of new cases of Buruli ulcer every year also remains a major public health problem. Buruli ulcer (BU) is a disabling disease and the presentation of lesions is frequently severe. A feature of $\mathrm{BU}$ and HIV coinfection is the rarity of cases, which makes its study difficult, but, nevertheless, important to study its seroprevalence, biological data, risk factors and genetic diversity. The purpose of this study is to explore the comorbidity of Buruli ulcer and HIV by evaluating HIV seroprevalence in BU patients, assessing demographic data, reviewing biological data including CD4+ $\mathrm{T}$ cell count, hemoglobin levels, and viral loads, and evaluating clinical and therapeutic data. Methods: This is a cross-sectional study including only BU patients confirmed by Ziehl Neelsen staining and IS 2404 PCR. The patients were hospitalized in the National Reference Center for Tsevie. They were recovered patients and patients undergoing outpatient treatment in the Gati and Tchekpo Deve treatment centers, respectively, within the Sanitary Districts of Zio and Yoto of the Maritime Region during the period from August 2015 to March 2017. Results: The number of HIV-positive BU patients is 4 out of a total of $83 \mathrm{BU}$ patients. All patients are HIV-1 positive. HIV prevalence among BU patients is $4.8 \%$ compared to $2.5 \%$ nationally and $3 \%$ at regional level. Three BU patients are seropositive out of a total of 46 female patients while one patient under 15 years is seropositive out of a total of 37 male $\mathrm{BU}$ patients. There are a greater proportion of female patients with BU/HIV coinfections. Half of the BU/HIV positive patients (BU/HIV+) have a CD4+ TL of fewer than 500 cells/ $\mu$ land the difference is significant between those of the BU HIV- and those of the BU/HIV+ patients. Two patients have unde-
\end{abstract}


tectable viral loads while the other two have more than 1000 copies $/ \mathrm{ml}(33,000$ and 1,100,000 copies $/ \mathrm{ml}$ ). Anemia is significantly present in BU/HIV+ patients with a $\mathrm{p}$-value $=0.003$. Half of $\mathrm{BU}$ patients have primary education, while three-quarters of BU/HIV+ patients have no education. All patients are either in stage I or stage II of the AIDS WHO classification. All patients are on first line ARV therapy and only ARV nucleoside reverse transcriptase inhibitors (NRTIs) are used. Conclusion: In Togo, the prevalence of HIV in BU patients, although higher, is not significantly different from that of national and regional. The relatively high CD4+ LT levels of relatively high BU HIV + patients, undetectable viral loads, and AIDS WHO stages I and II indicate good quality management. Author Summary: Buruli ulcer disease (BUD) is a mycobacterial skin disease that leads to extensive ulcerations and causes disabilities in approximately $25 \%$ of the patients. Co-infection with HIV is described by the authors through the prism of risk factors and the severity of ulcerations. Healing time is described as longer than in BU/HIV- patients. The scarcity of cases seems to be an obstacle for further study. Noteworthy are the study of cases in Benin and the study of cohort cases in Cameroon. However, no study appears to be based on the seroprevalence of this morbid association, the biological data and the antiretroviral regimens. These regimens, if poorly instituted, conflict with antimycobacterial drugs against Buruli ulcer. This study, although confronted with the particular configuration of Togo, a country with a low HIV prevalence of $2.8 \%$ national prevalence and an average of 55 cases of Buruli ulcer per year, is studying the biological aspects of co-infection HIV/BU, including seroprevalence of HIV, CD4+ LT levels, patient viral load and hemoglobin levels and ARV regimens. This study shows the need for future studies, including the study of the genetic diversity of circulating Mycobacterium ulcerans strains in Togo and the study of Buruli ulcer co-infection/HIV and tuberculosis.

\section{Keywords}

Buruli Ulcer, Coinfection Buruli Ulcer and HIV, HIV Seroprevalence, Mycobacterium ulcerans, TOGO

\section{Introduction}

Despite the various sustained efforts through National HIV/AIDS Programs (NACPs) in sub-Saharan African countries, particularly in West Africa, the incidence of HIV infection in the population remains a real public health problem given the morbidity of the disease. Buruli ulcer is a real public health challenge, considering the virulence of the disease caused by the production of mycolactone, a toxin with cytotoxic activity, immunomodulatory [1] and the necrotizing nature of dermal tissues or even bone, and remains the third most common tropical mycobacterial disease after tuberculosis and leprosy [2]. Buruli ulcer may be localized or disseminated [3], rarely chronic but often induces aesthetic, 
functional and life-threatening sequelae [4]. BU patients are often diagnosed by the clinic with or without biological confirmation according to WHO recommendations [5]. The biological diagnosis is made either by the Ziehl Neelsen staining method for acid-fast bacilli (AFB), by histopathology, or by the Polymerase chain reaction (PCR) method. The bacteriological culture is not often used for diagnosis. In sub-Saharan Africa, only Ziehl Neelsen staining is often available in the sites for BU confirmation [6]. WHO recommends at least two methods for biological confirmation of BU cases. Most cases of BU present as dermal ulcerations. The most severe cases, in particular osteomyelitis, often become complicated, leading either to amputations, or vicious retractions of skin leading to the loss of movement and these severe cases are described more frequently with co-infection with HIV, as well as the disseminated cases of BU [7].

The combination of HIV and BU thus becomes a morbid pairing whose severity of symptoms constitutes a real problem that deserves a study in order to appreciate the different proponents. The aim of this study was to evaluate HIV seroprevalence in BU patients and to study biological data, including CD4+ T lymphocytes cell count, anemia, viral loads, and antiretroviral therapy (ARV) introduced. This study aims to study the comorbidity of BU and HIV. Specifically, the objectives are to determine the prevalence of HIV in BU patients in Togo, to study demographic data, to evaluate biological data such as HIV type, assay hemoglobin, CD4+ T lymphocytes, measurement of viral loads, and, finally, to evaluate the clinical and therapeutic data.

\section{Methods}

\section{Study Setting and Design}

In Togo, the National Reference Center for Buruli Ulcer patients in Tsevie has the highest number of cases per year and the Zio and Yoto districts are the largest providers of cases. This is a cross-sectional study that included 83 patients. Patients are those hospitalized in the National Reference Center for BU patients in Tsevie, patients being treated in the Gati and Tchekpo Deve outpatient treatment centers with high prevalence of BU patients, respectively, in the health districts of Zio and Yoto located in the Maritime Region. And, finally, the recovered patients in these two health districts during the period from 15 August 2015 to 31 March 2017. These patients were selected in order to have an overview of the prevalence of HIV among BU patients in Togo and to study biological data.

\section{Patient Recruitment}

All enrolled cases are those who had biological confirmation through the identification of AFB from a lesion sample by the Ziehl-Neelsen technique at CHR-Tsevie and/or by PCR IS2404 classical technique of the Mastercycler type EPPENDORF, 53322KO58 at the National Institute of Hygiene (INH) of Lomé.

HIV testing was performed on blood samples from patients who were counseled and gave consent. The HIV test is carried out according to the WHO strategy-based national algorithm in which an initial screening test is carried out, and 
if the latter is found to be positive, a second specific test is carried out for the confirmation and the type of HIV [8]. In this study, the first test was "Determine ALERE HIV 1/2 0 (Alere Medical Co. Ltd., Chiba, Japan) or ELISA MUREX TM (DiaSorin SpA, Dartford, UK), the second test was HIV Tri Dot TM (Mitra \& Co. Pvt. Ltd., New Delhi, India).

CD4+ LT counting is performed using the BD FACSCount (BD Biosciences, San Jose, CA, USA) flow immunocytometry technique with BD FACSCount TM reagents CD4 Reagent absolute value/reference percentage class number 339,010 (BD Biosciences, San José, CA, USA) of the CHR Tsevie laboratory, which is the regional reference laboratory for HIV biology.

According to the national guidelines, ARV treatment is conditioned, inter alia, at the WHO clinical stage and at a CD4+ LT level of less than 500 cells/ $\mu \mathrm{l}$ of blood for stage I and II patients [8]. Viral loads are analyzed in the Laboratory of Molecular Biology and Immunology of the Faculty of Health Sciences of Lomé (BIOLIM) for HIV positive patients. The technique used is the measurement of plasma RNA according to the NASBA technique on NucliSENS EasyQ equipment with NucliSENS HIV-1 reagents version 2.0.

\section{Statistical Analyses}

The prevalences and rates were compared using Fisher's exact test with a 95\% confidence interval.

\section{Ethical Considerations}

The clinical and epidemiological information of patients enrolled from August 2015 to March 2017 is available on the BUO1 database (Access 2003, Microsoft Cooperation, Redmond, WA). The information was recorded using an elaborated fact sheet including demographic data and biological data. The data are anonymous. Informed consent was signed by all enrolled persons or their legal guardian after being well informed of the objectives of the study. The National Program for the Control of Buruli Ulcer, Leprosy and Lean approved the study project ( $\mathrm{N}^{\circ}$ 159/2015/MS/DGS/DSSP/PNLUB-LP) as well as the Bioethics Committee for Health Research (CBRS) (Avis $\mathrm{N}^{\circ}$ 30/2017/CBRS of October 9, 2017). All confirmed cases of HIV have been referred to the Maritime Region HIV Therapeutics Committee and the Buruli Ulcer Management Center.

\section{Results}

From August 15, 2015 to March 31, 2017, 83 cases of BU patients hospitalized, being treated as outpatients, or recovered were enrolled for HIV testing. Four cases were positive for HIV 1: three cases among females between 35 and 50 years, 1 male case 12 years of age.

Comparison of HIV prevalence among BU patients in Togo is shown in Table 1.

No BU patient group has an HIV prevalence statistically different from national prevalence. National prevalence is included in the CI $95 \%$ of the respective prevalence of the UB patient groups.

Evaluation of the different demographic, biological, clinical and therapeutic data of patients with BU/HIV - and BU/HIV+ (Table 2). 
Table 1. Comparative table of HIV prevalence among BU patients.

\begin{tabular}{|c|c|c|c|c|c|c|c|c|c|}
\hline & $\begin{array}{c}\text { Children under } \\
15 \text { years with } \\
\text { BU }(n=48)\end{array}$ & $\begin{array}{c}\text { Children } \\
\text { under } 15 \\
\text { years }\end{array}$ & $\begin{array}{c}\text { Women }>15 \\
\text { years with BU } \\
(n=26)\end{array}$ & $\begin{array}{c}\text { Women }> \\
15 \text { years }\end{array}$ & $\begin{array}{c}\text { Men }>15 \\
\text { years with BU } \\
(n=9)\end{array}$ & $\begin{array}{l}\text { All BU } \\
\text { patients } \\
(n=83)\end{array}$ & $\begin{array}{l}\text { All BU } \\
\text { patients } \\
(n=83)\end{array}$ & $\begin{array}{l}\text { National } \\
\text { prevalence }\end{array}$ & $\begin{array}{l}\text { Regional } \\
\text { prevalence }\end{array}$ \\
\hline $\begin{array}{l}\text { Prevalence } \\
\text { du VIH (\%) }\end{array}$ & $2.1 \%$ & $5.6 \%$ & $12.5 \%$ & $3.1 \%$ & $0.0 \%$ & $1.7 \%$ & $4.8 \%$ & $2.5 \%$ & $3.0 \%$ \\
\hline $95 \%$ CI & \multicolumn{2}{|c|}{$[0.0-10.4]$} & \multicolumn{2}{|c|}{$[2.7-32.4]$} & \multicolumn{2}{|c|}{$[0.0$ - 36.9] } & \multicolumn{3}{|c|}{ [13.0 - 11.9] } \\
\hline
\end{tabular}

Table 2. Comparative table of different demographic data, biological, clinical and thera peutic of patients BU/HIV- and of BU/HIV+ patients.

\begin{tabular}{|c|c|c|c|c|}
\hline & Total (\%) & $\begin{array}{c}\text { Patients } \\
\text { UB/HIV- (\%) }\end{array}$ & $\begin{array}{c}\text { Patients } \\
\text { UB/HIV+ (\%) }\end{array}$ & $\mathrm{p}$ value \\
\hline Number & $83(100.0)$ & $79(95.2)$ & $4(4.8)$ & \\
\hline \multicolumn{5}{|c|}{ Gender } \\
\hline Male & $37(100.0)$ & $36(97.3)$ & $1(2.7)$ & \multirow{2}{*}{$\mathrm{p}=0.62$} \\
\hline Female & $46(100.0)$ & $43(93.5)$ & $3(6.5)$ & \\
\hline \multicolumn{5}{|c|}{ Age } \\
\hline $0-14$ years & $46(100.0)$ & $45(97.8)$ & $1(2.2)$ & \multirow{2}{*}{$\mathrm{p}=0.32$} \\
\hline$\geq 15$ years & $37(100.0)$ & $34(91.9)$ & $3(8.9)$ & \\
\hline \multicolumn{5}{|c|}{ Educational level } \\
\hline No education & $19(100.0)$ & $16(84.2)$ & $3(15.8)$ & \multirow{4}{*}{$\begin{array}{c}\mathrm{p}=0.035 \\
\mathrm{RR}=10.11 \\
95 \% \mathrm{CI}= \\
{[1.11-92.6]}\end{array}$} \\
\hline Primary studies & $58(100.0)$ & $57(98.3)$ & $1(1.7)$ & \\
\hline Secondary studies & $5(100.0)$ & $5(100.0)$ & $0(0.0)$ & \\
\hline Tertiary studies & $1(100.0)$ & $1(100.0)$ & $0(0.0)$ & \\
\hline \multicolumn{5}{|c|}{ HIV screening } \\
\hline VIH type & & & HIV 1 & \\
\hline Old infection & & & 2 & \\
\hline Patients newly screened & & & 2 & \\
\hline \multicolumn{5}{|c|}{ Hemoglobin rate } \\
\hline Hemoglobin rate $95 \%$ CI & & $\begin{array}{c}12.02 \\
{[11.77-12.28]}\end{array}$ & $\begin{array}{c}10.15 \\
{[8.55-11.74]}\end{array}$ & $\mathrm{p}=0.003$ \\
\hline \multicolumn{5}{|c|}{ CD4+ LT rate } \\
\hline$[0-500]$ cells $/ \mu \mathrm{l}$ & & 1 & 2 & \multirow{2}{*}{$\mathrm{p}=0.006$} \\
\hline$\geq 500$ cells $/ \mu \mathrm{l}$ & & 73 & 2 & \\
\hline Cells average/ $\mu \mathrm{I}$ IC95\% & & $\begin{array}{c}1059 \\
{[970-1148]}\end{array}$ & $\begin{array}{c}539 \\
{[133-945]}\end{array}$ & $\mathrm{p}=0.01$ \\
\hline \multicolumn{5}{|c|}{ HIV viral load } \\
\hline Undetectable & & & 2 & \\
\hline$[40-1000]$ copies $/ \mathrm{ml}$ & & & 0 & \\
\hline$\geq 1000$ copies $/ \mathrm{ml}$ & & & 2 & \\
\hline
\end{tabular}




\begin{tabular}{|c|c|}
\hline \multicolumn{2}{|c|}{ HIV WHO stages } \\
\hline Stage $1-2$ & 4 \\
\hline Stage $3-4$ & 0 \\
\hline \multicolumn{2}{|c|}{ ARV regimen } \\
\hline $\mathrm{AZT}+3 \mathrm{TC}+\mathrm{EFV}$ & 1 \\
\hline $\mathrm{TDF}+3 \mathrm{TC}+\mathrm{EFV}$ & 1 \\
\hline $\mathrm{ABC}+3 \mathrm{TC}+\mathrm{EFV}$ & 1 \\
\hline $\mathrm{AZT}+3 \mathrm{TC}+\mathrm{NVP}$ & 1 \\
\hline
\end{tabular}

Females are the most represented and the most infected by HIV. Patients above 15 years old are more infected. The risk of HIV positive in uneducated patients equals 10 times the risk in educated patients and this difference is statistically significant with $p=0.035$. All the patients are infected by HIV1. Hemoglobin and CD4+ LT levels in HIV positive patients were on average significantly lower than those in HIV negative patients $(\mathrm{p}=0.003, \mathrm{p}=0.01)$. Half of the patients had undetectable viral load. All of the patients are in stage 1 or 2 of AIDS WHO categorization. All of the patients were placed under first-line ARVs.

\section{Discussion}

This study was conducted in a context of countries with low HIV prevalence with an average of 55 cases of Buruli ulcer per year. Analysis of the epidemiological situation of HIV/AIDS in Togo showed the generalized nature of the epidemic with an average prevalence of $2.5 \%$ in the general population aged $15-49$ [8] (EDST III). It also confirmed the predominance in women with $3.1 \%$ in women compared with $1.7 \%$ in men. In this study, the prevalence of HIV in BU patients is higher at $4.8 \%$, although this is not statistically different from the EDST III prevalence, which is included in the $95 \%$ CI of the prevalence of BU patient groups. There is also a trend towards feminization, that is, $12.5 \%$ against $0 \%$ for the male sex. In this study, the prevalence of HIV in BU patients is almost the double of that found by RC Johnson et al. in Benin in 2008 [9], who in their case control study, found a prevalence of $2.6 \%$.

Few data are available on BU and HIV coinfection, but according to O'Brien et al. in 2014 [10], African countries endemic to Buruli ulcer are also HIV-infected, with a proportion of $1 \%$ HIV to $5 \%$ BU-HIV coinfection. In the studies in Cameroon, HIV prevalence in $\mathrm{BU}$ patients is three to six times higher than in the general population, i.e. $37 \%$ against $7 \%$ for women, $20 \%$ against $5 \%$ for men and $4 \%$ for women $0.7 \%$ for children [11]. In Ghana, HIV prevalence is five times higher among BU patients, i.e. 5\% compared with $0.9 \%$ [12]. This corroborates the results of this study. The only bias could be the reduced number of our sample.

According to the results of this study, the most infected BU/HIV patients were 
those without education and those with only primary education. In Togo women are also generally less educated than men. Although few studies seem to dwell on this aspect, the risk of HIV positivity in poorly educated patients is 10 times higher than the risk in educated patients and this difference is statistically significant with $\mathrm{p}=0.035$.

The type of HIV detected in our study is $100 \%$ HIV 1 . This corresponds to the national data in which HIV 1 is detected in a proportion of $99.1 \%$ for HIV 1 , $0.4 \%$ for HIV 2 and $0.5 \%$ for HIV 1/HIV 2 coinfection [8].

All patients are in stages I and II of Buruli ulcer WHO lesions categories. These are patients with simple ulcerations in total remission. It is therefore necessary to set up systematic screening of HIV as soon as patients are registered with BU in order to study the future the impact of HIV on the severity of cases of Buruli ulcer, in particular the disseminated forms and bone lesions often associated with HIV-BU co-infections, and thus to define more precisely the healing times of these patients [13], since the authors' time seems to be longer.

The results of blood analysis reveal anemia in BU/HIV patients, but is more pronounced in BU/HIV+ patients with a significant difference $(\mathrm{p}=0.003)$. These results confirm the work of Hercberg $S$ et al. [14] that anemia is specific to sub-Saharan African BU patients. This predisposition is associated with the polymorphism of the NRAMP1 iron transporter gene [15]. This is an iron deficiency anemia present during mycobacterial diseases due to sequestration in the phagosomes of the ferrous ion $\left(\mathrm{Fe}^{2+}\right)$ of the organism, and the inability of the NRAMP1 to recover it [16]. This disease state would be aggravated by HIV coinfection [17], serological status and AIDS WHO stage.

On the other hand, the results of the hemoglobin levels reveal a good general state of the BU patients which corroborate the results of Connor DH et al. [18] which explains this by the mycolactone inhibitory action on the production of tumor necrosis factor (TNF), usually responsible for fevers and catechesis [19].

The immune mechanism for HIV co-infection and other diseases is clearly defined and studied. Examples include HIV/tuberculosis co-infection, another mycobacterial disease, where immunity is bidirectional and synergistic with a strong predisposition to CD4+ T-cell immunodeficiency which corresponds to a risk factor. On the other hand, the immune mechanism of protection for Buruli ulcer remains poorly understood [20]. The results of this study show that the $\mathrm{CD} 4+\mathrm{LT}$ level of BU/HIV+ patients is lower than that of BU/HIV negative patients-both for levels below 500 cells/ $\mu \mathrm{l}(133$ - 945) and above 500 cells/ $\mu \mathrm{l}(970$ 1148). Two findings emerge from these results: with regard to BU/HIV co-infection, immunity based on helper T lymphocytes is reduced, which could constitute a real risk factor for severity of BU according to Christinet et al. [11]. However, Tuffour J et al. [21] state that the level of CD4+ LT is not always correlated with the severity of ulcer disease, as confirmed by the results, since for BU/HIV negative immunity is preserved with high levels of CD4+ LT of up to 2000 cells/ $\mu$ l.

According to Shastri S et al. [22], the immune response to mycobacterial dis- 
eases is mediated by the activation of CD4+ LT by macrophages and is thus probably crucial for Buruli ulcer. Especially since large phagosomes produced by Mycobacterium ulcerans are indications of the multiplication of the pathogen in the phagocytes. This plays an important role in the early hours of the infection, which leads to a reduction in the release of interferon gamma (IFNgamma) [23], whose synergistic action with TNF potentiates the production of oxide metabolites nitric acid [24] to eliminate mycobacteria, hence the importance of CD4+ LT levels as much for the follow-up of UB HIV positive patients as for BU HIV negative patients.

The results of viral loads yielded undetectable results for two patients and viral loads above 1000 copies/ml (33,000 and 1,100,000 copies/ml). Since Togo is a country with similar care settings as in resource-constrained countries, it is often confronted with the difficulty of systematically measuring the viral load of all the patients detected and placing patients under ARV. The dosage of CD4+ LT remains a mandatory passage for treatment, but according to the work of Hoffmann CJ et al. in 2016 [25] only the viral load is the best argument for deciding on ARV treatment and for monitoring all the patients. It is therefore crucial that the viral load is systematic for vulnerable patients including BU patients.

The patients in this study were placed under first-line ARVs: AZT + 3TC + $\mathrm{EFF}, \mathrm{TDF}+3 \mathrm{TC}+\mathrm{EFV}, \mathrm{AZT}+3 \mathrm{TC}+\mathrm{EFV}$ and $\mathrm{ABC}+3 \mathrm{TC}+\mathrm{EFV}$ for patients under 15 years of age. This corroborates the WHO recommendations [26] for whom due to the interactions between rifampicin and certain ARVs, the NNRTI component of the regimen should be changed by prescribing EFV instead of NVP and, if inhibitors of Protease would be prescribe the guidelines for tuberculosis/HIV [27] should be consulted for the proposed management.

This is all the more true as the onset of ARV treatment is specific in the case of co-infection for interactions with antimycobacterial treatments since nevirapine concomitantly with streptomycin would reduce Cmax and Cmin due to interaction with rifampicin. While concomitant use with cotrimoxazole would establish immunity and combat opportunistic infections. In this study, the patients were treated mainly with nucleoside and non-nucleoside inhibitors with only flat effavirenz recognized as a molecule potentiating the adverse effects of antimycobacterial treatments in particular claythromycin [28] often not used in treatments in Togo. It is therefore essential to provide routine screening of tuberculosis to all patients co-infected with BU/HIV, since this is a significant player in the ARV regimen.

\section{Conclusion}

The BU and HIV coinfection is a real public health problem that deserves more study. In Togo, the prevalence of HIV in BU patients, although higher, is not significantly different from that of national and regional. The HIV biological, clinical and therapeutical data indicate good quality management. The problem of HIV coinfection and tuberculosis is still evident, since it often resides in coun- 
tries endemic to tuberculosis, the treatment of which could lead to resistance to ARV. This study therefore raises the need for future studies on the management of the association of Buruli ulcer, HIV and tuberculosis and the integration of the efforts of the various national control programs concerned.

\section{Acknowledgements}

We thank Ms Phyllis EHLAN and the entire BIOLIM laboratory team for analyzing the viral loads as well as the entire laboratory team of CHR Tsevie.

We thank Dr Marta GUERRA for her review and comments of manuscript.

We thank the Community Health Officers and the heads of the health facilities of Gati and Tchekpo Deve.

We thank the PNLS, the DAWH for their technical support

We thank the PNLP-LP for the availability of the databases.

\section{Conflicts of Interest}

The authors declare no conflicts of interest regarding the publication of this paper.

\section{References}

[1] Boulkroun, S., Guenin-Macé, L., Thoulouze, M.I., et al. (2010) Mycolactone Suppresses T Cell Responsiveness by Altering Both Early Signaling and Posttranslational Events. The Journal of Immunology, 184, 1436-1444. https://doi.org/10.4049/jimmunol.0902854

[2] Adle-Biassette, H., Huerre, M. and Breton, G. (2003) Non-Tuberculous Mycobacterial Diseases. Annales de Pathologie, 23, 216-235.

[3] Portaels, F., Silva, M.T. and Meyers, W.M. (2009) Buruli Ulcer. Clinics in Dermatology, 27, 291-305. https://doi.org/10.1016/j.clindermatol.2008.09.021

[4] Agbenorku, P. (2011) Multicenter Study of Buruli Ulcer Disabilities in the Head and Neck Region. Plastic Surgery International, 2011, Article ID: 647418. https://doi.org/10.1155/2011/647418

[5] WHO (2001) Buruli Ulcer: Diagnosis of Mycobacterium ulcerans Disease-A Manual for Health Care Providers. WHO, Geneva.

[6] Portaels, F., Johnson, P. and Meyers, W.M. (2001) Buruli Ulcer: Diagnosis of $M y$ cobacterium ulcerans Disease. WHO, Geneva, 200.

[7] Ouattara, D., Meningaud, J.P. and Saliba, F. (2002) Multifocal Forms of Buruli Ulcer: Clinical Aspects and Management Difficulties in 11 Cases. Bulletin de la Société de Pathologie Exotique, 95, 287-91.

[8] Rapport annuel 2015 des activites du PNLS-IST-TOGO.

[9] Johnson, R.C., Nackers, F., Glynn, J.R., et al. (2008) Association of HIV Infection and Mycobacterium ulcerans Disease in Benin. AIDS, 22, 901-903. https://doi.org/10.1097/QAD.0b013e3282f7690a

[10] O’Brien, D.P., et al. (2014) Management of BU-HIV Co-Infection. Tropical Medicine and International Health, 19, 1040-1047. https://doi.org/10.1111/tmi.12342

[11] Christinet, V., Comte, E., Ciaffi, L., Odermatt, P., Serafini, M., et al. (2015) Impact of Human Immunodeficiency Virus on the Severity of Buruli Ulcer Disease: Results of a Retrospective Study in Cameroon. Open Forum Infectious Diseases, 1, ofu021. 
https://doi.org/10.1093/ofid/ofu021

[12] Raghunathan, P.L., Whitney, E.A., Asamoa, K., et al. (2005) Risk Factors for Buruli Ulcer Disease (Mycobacterium ulcerans Infection): Results from a Case-Control Study in Ghana. Clinical Infectious Diseases, 40, 1445-1453. https://doi.org/10.1086/429623

[13] Johnson, R.C., Nackers, F., Glynn, J.R., de Biurrun-Bakedano, E., Zinsou, C., et al. (2008) Association of HIV Infection and Mycobacterium ulcerans Disease in Benin. AIDS, 22, 901-903. https://doi.org/10.1097/QAD.0b013e3282f7690a

[14] Hercberg, S., Chauliac, M., Galan, P., Devanlay, M., Zohoun, I., Agboton, Y., Soustre, Y., Auvert, B., Masse-Raimbault, A.M. and Dupin, H. (1988) Prevalence of Iron Deficiency and Iron-Deficiency Anaemia in Benin. Public Health, 102, 73-83. https://doi.org/10.1016/S0033-3506(88)80013-1

[15] Stienstra, Y., van der Werf, T.S., Oosterom, E., Nolte, I.M., van der Graaf, W.T., Etuaful, S., Raghunathan, P.L., Whitney, E.A., Ampadu, E.O., Asamoah, K., Klutse, E.Y., Meerman, G.J., Tappero, J.W., Ashford, D.A. and van der Steege, G. (2006) Susceptibility to Buruli Ulcer Is Associated with the SLC11A1 (NRAMP1) D543N Polymorphism. Genes \& Immunity, 7, 185-189.

https://doi.org/10.1038/sj.gene.6364281

[16] Van Zandt, K.E., Sow, F.B., Florence, W.C., Zwilling, B.S., Satoskar, A.R., Schlesinger, L.S. and Lafuse, W.P. (2008) The Iron Export Protein Ferroportin 1 Is Differentially Expressed in Mouse Macrophage Populations and Is Present in the Mycobacterial-Containing Phagosome. Journal of Leukocyte Biology, 84, 689-700. https://doi.org/10.1189/jlb.1107781

[17] Ferede, G. and Wondimeneh, Y. (2013) Prevalence and Related Factors of Anemia in HAART-Naive HIV Positive Patients at Gondor University Hospital, Northwest Ethiopia. BMC Hematology, 13, Article No. 8. https://doi.org/10.1186/2052-1839-13-8

[18] Connor, D.H. and Lunn, F. (1966) Buruli Ulceration: A Clinicopathologic Study of 38 Ugandans with Mycobacterium ulcerans Ulceration. Archives of Pathology, 81, 183-189.

[19] Barnes, P.F., Lu, S., Abrams, J.S., Wang, E., Yamamura, M. and Modlin, R.L. (1993) Cytokine Production at the Site of Disease in Human Tuberculosis. Infection and Immunity, 61, 3482-3489. https://doi.org/10.1128/IAI.61.8.3482-3489.1993

[20] Girma, M., Teshome, W., Petros, B. and Endeshaw, T. (2014) Cryptosporidiosis and Isosporiasis among HIV-Positive Individuals in South Ethiopia: A Cross Sectional Study. BMC Infectious Diseases, 14, 100.

[21] Tuffour, J., Owusu-Mireku, E., Ruf, M.-T., Aboagye, S., Kpeli, G., Akuoku, V., Pereko, J., Paintsil, A., Bonney, K., Ampofo, W., Pluschke, G. and Yeboah-Manu, D. (2015) Challenges Associated with Management of Buruli Ulcer/Human Immunodeficiency Virus Coinfection in a Treatment Center in Ghana: A Case Series Study. American Journal of Tropical Medicine and Hygiene, 93, 216-223. https://doi.org/10.4269/ajtmh.14-0571

[22] Shastri, S., Naik, B., Anita Shet, A., Bharat Rewari, B. and De Costa, A. (2013) TB Treatment Outcomes among TB-HIV Co-Infections in Karnataka, India: How Do These Compare with Non-HIV Tuberculosis Outcomes in the Province? BMC Public Health, 13, Article No. 838. https://doi.org/10.1186/1471-2458-13-838

[23] Yeboah-Manu, D., Peduzzi, E., Mensah-Quainoo, E., Asante-Poku, A. and Ofori-Adjei, D. (2006) Systemic Suppression of Interferon-Gamma Responses in Buruli Ulcer Patients Resolves after Surgical Excision of the Lesions Caused by the Extracel- 
lular Pathogen Mycobacterium ulcerans. Journal of Leukocyte Biology, 79, 1150-1156. https://doi.org/10.1189/jlb.1005581

[24] Ding, A.H., Nathan, C.F. and Stuehr, D.J. (1988) Release of Reactive Nitrogen Intermediates and Reactive Oxygen Intermediates from Mouse Peritoneal Macrophages: Comparison of Activating Cytokines and Evidence for Independent Production. The Journal of Immunology, 141, 2407-2412.

[25] Hoffmann, C.J., Maritz, J. and van Zyl, G.U. (2016) CD4 Count-Based Failure Criteria Combined with Viral Load Monitoring May Trigger Worse Switch Decisions than Viral Load Monitoring Alone. Tropical Medicine and International Health, 21, 219-223. https://doi.org/10.1111/tmi.12639

[26] OMS (2014) Traitement de l'Infection a Mycobacterium ulcerans (Ulcère de Buruli): Recommandations a l'Intention des Agents de Santé.

[27] Organisation mondiale de la Santé (2010) Traitement Antirétroviral de l'Infection A VIH chez L'Adulte et L'Adolescent: Recommandations pour une Approche de Santé Publique-Mise a Jour 2010. Organisation Mondiale de la Santé, Genève, Suisse.

[28] O’Brien, D.P., Comte, E., Ford, N., Christinet, V. and du Cros, P. (2013) Moxifloxacin for Buruli Ulcer/HIV Coinfected Patients: Kill Two Birds with One Stone? AIDS (London, England), 27, 2177-2179.

https://doi.org/10.1097/QAD.0b013e32836268f4 